\title{
Role of Radiotherapy in Kaposi's Sarcoma: Review of the Literature
}

\author{
(1) Ijpek PInar ARAL, 1 (1) Gonca ALTINIŞIK INAN, ${ }^{2}$ (D) Süheyla AYTAÇ ARSLAN, ${ }^{2}$ (D) Selcan TEKIN, ${ }^{3}$ \\ (1) Neşe GÖÇER GÜROK, ${ }^{4}$ (1) Alaettin ARSLAN, ${ }^{5}$ (1) Yılmaz TEZCAN²
}

\author{
'Department of Radiation Oncology, Nevşehir State Hospital, Nevşehir-Turkey \\ 2Department of Radiation Oncology, Ankara Yıldırım Beyazıt University Faculty of Medicine, Ankara-Turkey \\ ${ }^{3}$ Department of Radiation Oncology, Ankara Sanatoryum Hospital, Ankara-Turkey \\ ${ }^{4}$ Department of Dermatology, Elazığ Fethi Sekin City Hospital, Elazığ-Turkey \\ ${ }^{5}$ Department of Radiation Oncology, Kayseri City Hospital, Kayseri-Turkey
}

\begin{abstract}
SUMMARY
Radiotherapy (RT) is an effective treatment for local palliation of Kaposi's sarcoma. However, there is no standardized RT dose and technique. Usually, electrons or low-energy photons are used, and various bolus materials are utilized for better dose distribution. High treatment response rates have been reported in all RT schemes. When the literature is examined in terms of dose and schema, for cutaneous lesions, single fraction treatments $<8$ Gy are less effective in terms of complete response (CR), and more effective results were obtained in total doses of $20 \mathrm{~Gy}$ and above. A total of $15 \mathrm{~Gy}$ for oral lesions, $20 \mathrm{~Gy}$ in eyelid conjunctival and scrotal lesions, and $30 \mathrm{~Gy}$ for cutaneous lesions are recommended. Planning target volume margins are defined as $2 \mathrm{~mm}-5 \mathrm{~mm}$ for orthovoltage devices and $0.5-2 \mathrm{~cm}$ for other treatments. In this study, we aimed to review the RT studies presented in the literature.

Keywords: Kaposi’s sarcoma; palliation; radiotherapy; review.

Copyright $\odot$ 2021, Turkish Society for Radiation Oncology
\end{abstract}

\section{Introduction}

Kaposi's sarcoma (KS) was first described in 1872 by Doctor Moritz Kaposi. KS is a vasculoendothelial malignancy that frequently presents with multiple skin lesions and may also involve lymph node (LN), mucosa, and visceral involvement.[1] The male/female ratio is 2 for all subgroups. In GLOBOCAN 2018 data, 41.799 new KS were diagnosed, and 19,902 KS-related deaths were reported.[2] Although not common in oncology clinics, it is the most common malignancy in children in Africa and human immmunodeficiency virus (HIV)-positive patients.[3-5]

The cutaneous lesions can be appeared in different colors and characteristics depending on subtype and stage. The lesions may be seen clinically in the form of pink patches, purplish, blue, or black nodules/plaques or polyps.[6] The dermoscopy can be used to differentiate vascular tumors.[7] The lesions may be accompanied by pain, bleeding, pruritus, lymphedema, or superinfection. [8] The punch biopsy (or rarely excisional biopsy) is required for definitive diagnosis. [6]

Regardless of the clinical subtype, cutaneous lesions usually consist of three stages: Patch, plague, and nodular stage.[1] In the patch phase, endothelial cell proliferation is observed in the reticular dermis. Inflammatory changes are present, plasma cells and lymphocytic cells infiltration may occur. The morphological changes can be observed in dermal vessels and adnexal structures. In the plaque stage, there is proliferation of spindle cells in the dermis (sometimes in the subcutaneous area) irregular dermal collagen increases. Erythrocyte 
extravasation and hemosiderin-laden macrophages can be seen and neo-angiogenesis occurs. In the nodular phase, the spindle cells have mild and moderate atypia; chronic inflammatory reaction predominates. Lymphocyte, plasma cell, and dendritic cell infiltration can be observed. There is no relationship between the pathological evaluation and prognosis; however, prognosis is adversely affected only in the presence of high atypia/anaplastic cells. [6]

KS is not only cutaneous but also mucosal, visceral, and nodal involvement may develop at first admission or during the disease. The visceral involvement rate is more than $50 \%$ in HIV-related type. The gastrointestinal system (GIS) involvement is most observed. It is manifested by symptoms such as weight loss, abdominal pain, and diarrhea regardless of skin involvement. The pulmonary extension is the second most common extra-cutaneous KS involvement after GIS. The patient may present with cough, dyspnea, and hemoptysis.[9]

The human herpesvirus (HHV) 8, HIV, immunosuppression; genetic factors; antimalarial therapies, and the use of angiotensin-converting enzyme inhibitors may play a role as risk factors.[10,11]

\section{Kaposi's Sarcoma-The Clinical Subgroups}

\section{Classic KS (CKS)}

It is the form described by Moritz Kaposi in 1872. It is common in males (Males/Females; $=10-15 / 1$ ) of advanced age $(60<)$ of Mediterranean, Eastern Europe, Jewish, and South American origin.[12] Advanced age and HHV-8 are the main risk factors.[6] The initial complaints are often patchy pigmented lesions in the lower extremities. Although not frequent, mucosal $(<5 \%)$, visceral $(<10 \%)$, and $\mathrm{LN}(<10 \%)$ involvement may occur. $[6,12,13]$ It is usually not aggressive, manifests as chronic skin lesions, progresses slowly, rarely fatal, and does not increase the risk of secondary malignancy. The median overall survey (OS) is 9.4 years; advanced age and immunosuppression are negative prognostic.[6] The localized lesions can be treated with surgery, radiotherapy (RT), and follow-up; systemic therapies are indicated in the presence of diffuse lesions or visceral involvement.[12]

\section{Endemic KS (EnKS)}

EnKS was first detected in children living in Central and Eastern Africa in the 1960s.[14-16] The male/female ratio is $2-3 / 1$. It is generally diagnosed in HIV-negative men aged 25-30 years and reported in the pediatric en- demic group and the median age in this group is 3 years. [10] The patients were HIV negative, and the EnKS was associated with HHV-8 positivity. Unlike other forms, $\mathrm{LN}$ involvement is more common than skin lesions. Afterward, endemic HIV was detected in the region. In the last two to three decades, KS observed at a young age showed a shift toward HIV-related type.[4] The prognosis varies widely from indolent skin lesion to aggressive fatal systemic disease.[13] Depending on the course of the disease, local or systemic therapies are preferred.

\section{Iatrogenic KS (IKS)}

It is frequently observed after solid organ transplantation (OT). IKS was first described in patients who used long-term immunosuppressive drugs after OT in the 1970s. [17] In addition to OT, KS may also develop due to long-term use of corticosteroids and other malignancies/treatments where immunosuppression is observed. The skin lesions are predominating, mucosal involvement is $20 \%$, visceral involvement is $20-50 \%$, and $\mathrm{LN}$ involvement is $20-40 \%$. The incidence of $\mathrm{KS}$ in cases with OT is $8.8 / 100.000$.[18] The median time to development of KS after OT is 13 months, but the interval may range from a few weeks to 18 years. [6] It is rarely aggressive.[13] In a recent French study, 5 years and 10 years OS were reported as $85 \%$ and $75 \%$.[19] There are insufficient data on prognostic factors. [6]

\section{Epidemic KS (EpKS)}

It is the HIV-related subtype that is commonly seen in homosexual men and it is usually aggressive. EpKS was first described in the USA in the early 1980s. [17] In addition to cutaneous lesions, mucosal involvement is observed in $30-40 \%$, visceral involvement is observed in $20-40 \%$, and LN involvement is observed in $25 \%$ cases. Visceral involvement is also dominant in GIS and systemic symptoms (fever, weight loss, etc.) are initial symptoms. KS is the most common malignancy in HIV-positive patients. The lower CD4 cells increase the risk of developing KS.[6] EpKS may show an indolent or aggressive course. The patients need antiretroviral drugs and systemic chemotherapy (CT). Especially after use the effective combined antiretroviral therapies in HIV treatment, the incidence of KS decreased after 1995. The mortality of EpKS is also reduced with effective treatments. The median OS in Western countries is around 2 years. The presence of other concomitant HIV-related diseases, age 50 and older, HHV-8 viremia, and CD4 low are negative prognostic factors. [6] Combined antiretroviral therapies for HIV have a positive impact on the prognosis of EpKS but may not be suffi- 
cient, especially in advanced diseases. In this case, liposomal anthracycline-based CT and targeted agents are thought to be more widely used in the future. $[3,13,20]$

\section{Treatment of Kaposi's Sarcoma}

Surgery, RT, topical, intralesional therapies, CT, and electro-CT can be preferred in the treatment of local KS. No controlled randomized trials are comparing for local treatments. [6] Surgery may be tried in cases with good margins and cosmetically acceptable, but it has high recurrence rates. The $\mathrm{CO}_{2}$-laser and superficial cryotherapy can be applied in superficial lesions and have a response rate of $80-90 \%$, but it causes hypopigmentation in some cases. Intralesional CTs are another treatment option and have a response rate of around $70 \%$. Brambilla et al.[21] applied intralesional vincristine to $151 \mathrm{KS}$ patients, and a response rate of $98.7 \%$ was achieved. Electrochemotherapy is a new and interesting treatment and it is aimed to increase intratumoral CT uptake with the help of electropolarization. The most used CT is bleomycin. In current prospective studies, $65-89 \%$ complete response (CR) was obtained with electrochemotherapy. [22-24] RT is one of the effective treatments that will be discussed in detail.

In the presence of systemic disease, anthracyclinebased CT and immunotherapy are applied. Furthermore, antiviral may be administered in case of infection such as HIV.[25] Treatment preference is determined by clinical subtype and patient's complaints. In systemic therapies, the aim is not to cure but to improve disease control and quality of life. Pegylated liposomal doxorubicin, paclitaxel interferon alfa-2a or $2 b$, and antiangiogenic agents (pomalidomide/lenalidomide/ bevacizumab) can be applied for this purpose.[6]

\section{Literature Search}

A broad search was conducted between November 2019 and December 2019 on PubMed (National Library of Medicine) using all fields and entering "Kaposi Sarcoma, Radiotherapy," "Kaposi-Sarkom, Strahlentherapie," and "Kaposi Sarkom, Radyoterapi." Studies that including at least 5 patients, published after 1990, written in English, German, or Turkish, and detailed RT dose technical and outcome details were included in the study. Studies with fewer than 5 patients, written language was not English, German, or Turkish, published before 1990, without RT detail was excluded from the study. The 36 original articles were found to meet our criteria and RT techniques, treatment outcome, and side effect data are summarized in Table 1.

\section{Role of RT in Kaposi's Sarcoma Treatment}

RT has been used safely in the local treatment of KS for many years. The most com mon indications for cutaneous lesions are pain, bleeding, pruritus, and edema. [1] RT is an effective treatment option not only in cutaneous lesions but also in mucosal lesions, especially in the oral cavity. Although oral cavity lesions are seen in all subtypes, it is the most common in epidemic type. Oral lesions are most commonly localized in hard palate, gingival, and dorsal tongue. Lesions may cause complaints such as pain, bleeding, and chewing difficulties due to local detrusion. [9] In this case, RT is indicated for palliative purposes. Besides, RT may be applied for eyelid, conjunctiva, genital area, and visceral organ involvement. [26,27]

KS is a radiosensitive tumor and a response rate of $70-90 \%$ is obtained in both cutaneous and extracutaneous lesions (Table 1).[13] In the study by Donato et al.,[28] who evaluated $18 \mathrm{KS}$ patients, $83.3 \% \mathrm{CR}$ was obtained in patients.

Akmansu et al.[29] reported in their study (2011), CR rates were $86.7 \%$ at 6 -month control and $93.3 \%$ at 12-month control. In Teke et al.[30] study, 45.5\% CR and $36.4 \%$ partial response (PR) were obtained by RT. High response rates are reported in the control of symptoms, especially pain and pruritus.

In addition to the high RT response rates, palliation shows a long-term persistence. Data on whether the effect of RT is permanent in the long term have been reported in classical KS studies because of its long survival values. For example, Akmansu et al.[29] evaluated 31 CKS lesions and 93\% CR was observed in the $1^{\text {st }}$ year control and this rate was not changed in the 5-year control. In the Kasper et al.[31] study, high-dose-rate (HDR) brachytherapy was applied to 16 lesions in a patient with non-HIV-associated and non-IKS, and 100\% CR was obtained, and no recurrence was observed during the 41-month median follow-up. In the literature sources with long-term data, the RT effect was found to be high persistent (Table 1).[27,29,31,32]

\section{Kaposi's Sarcoma-RT Techniques}

Due to the lack of prospective randomized studies, there is no standard approach to optimal RT techniques.[8] 
Electron and low energy photon are frequently preferred in Kaposi's sarcoma RT.[1] On the other hand, 3D, intensity-modulated RT (IMRT), volumetric arc therapy (VMAT) techniques can be used for planning. In the Park et al.[33] study, photons, electron, HDR, IMRT, and VMAT techniques were compared dosimetric, and it was observed that better dose values were achieved with VMAT in multiple lesions. In the study of Nicolini, electron versus photons (with VMAT) were compared and acceptable dose values and better treatment times were reported with VMAT.[18] In dosimetric studies that comparing modern RT techniques versus conventional techniques, similar dose values are observed. However, there are deficiencies in clinical trials where treatment response and side effects are evaluated together.

According to the width of the lesion, the applicator could be used in conventional electron treatments between 1.5 and $20 \mathrm{~cm}$.[26] Plexiglas tissue-equivalent material of 0.5 or $1 \mathrm{~cm}$ thickness can be supported to provide a dose peak on the skin surface. In photon treatments, opposite lateral fields are generally used. [34] Using low-energy photons, dose accumulation on the surface of the lesion is targeted.

Orthovoltage devices that can be used in low energy $(\mathrm{Kv})$ and used in superficial treatments have been applied in many clinics in the treatment of KS. $[35,36]$ $\mathrm{Kv}$ energy orthovoltage devices with 45 etkin $100 \mathrm{Kv}$ energy with 3-5 $\mathrm{mm}$ margin to $1 \mathrm{~cm}$ depth of effective treatments can be applied; however, in many clinics today, this treatment is not available.

Brachytherapy is an RT option in the treatment of KS. Clinical response and cosmetic results of brachytherapy have also been reported as excellent. In 2019, Ruiz et al.[37] applied 5 Gy $\times 5$ fractions (frc) HDR to a total of 5 lesions of 3 patients and achieved $100 \%$ $\mathrm{CR}$, and it was recommended to apply brachytherapy, especially in elderly patients and in cases where surgery and cosmetic results would be poor. On the other hand, Kasper et al.[31] applied 24-35 Gy/4-6 frc HDR to 16 patients and obtained $100 \%$ CR in the lesions. In summary, HDR brachytherapy is a successful alternative in elderly patients in cases where the cosmetic result of the operation is not good and lesions smaller than 2 $\mathrm{cm}$. In general, $24 \mathrm{~Gy} / 3 \mathrm{frc}$ doses were applied.[38,39]

Extremities are irregular surfaces, so bolus materials are used to control dose distribution. $[34,40]$ The bolus material contributes to homogeneous dose distribution in irregular areas and also contributes to the superstructure of the applied energy build-up point.[1] Mainly used boluses; are tissue equivalent substancepelxiglass and water bolus.
The choice of energy/technique should be determined with the help of a medical physicist considering the width and depth of the lesion.[34]

\section{Treatment Doses in Kaposi's Sarcoma RT}

In the literature review, different schemes ranging from $6 \mathrm{~Gy} / 1$ frc to 45 Gy were observed (Table 1).[40] The most commonly used doses were $8 \mathrm{~Gy} / 1$ frc; $30 \mathrm{~Gy} / 10$ frc, and 20 Gy/4-5 frc. Less frequently, $40 \mathrm{~Gy} / 20 \mathrm{frc}$ and $16 \mathrm{~Gy} / 4$ frc are also applied.[1] Fractional treatments are preferred if large area irradiation is to be performed. Furthermore, fractional therapies are more appropriate in mucosal lesions.[41]

Overall RT response rates are high. It has long been studied which of the different dosing schemes provides higher CR. In the Harrison et al.[35] study, 16 Gy/4 frc versus $8 \mathrm{~Gy} / 1$ frc doses were prospectively compared and there was no significant difference in response between the two doses. However, in the study of Stelzer et al.,[36] $8 \mathrm{~Gy} / 1$ frc versus $20 \mathrm{~Gy} / 10$ frc versus $40 \mathrm{~Gy} / 20$ frc were compared and significantly higher CR was observed in fractionated therapies. Kandaz et al.[42] reported that the fractionated therapies that total dose is over $20 \mathrm{~Gy}$ have a better response rate than $8 \mathrm{~Gy} / 1$ frc treatment. In summary, studies have shown that fractionated therapies are more effective in the literature data.

In a valuable study by Yildiz et al., the single dose of RT was prospectively examined for dose reduction. In the study of Yildız et al.,[43] 8 Gy/1 frc versus 6 Gy/1 frc were compared and significantly lower CR was observed in the $6 \mathrm{~Gy}$ arm. According to these data, less than 8 Gy in cutaneous single-fraction RT is not recommended. The studies that fractionated schemas evaluated and their entirety are available in the literature. In a study conducted by Singh et al.[44] in 2008, 24 Gy/12 frc versus $20 \mathrm{~Gy} / 5 \mathrm{frc}$ were prospectively randomized and there was no significant difference in terms of treatment response, side effect, and progression-free survey/OS. Geara et al.[45] (1991) reported a significantly lower objective response in the total dose $20 \mathrm{~Gy}$ arm compared to the 30 Gy arm ( $97 \%$ vs. $83 \% \mathrm{p}=0.04)$. Oysul et al.[46] (2008) presented the results of RT in 18 patients with CKS. Higher CR has been reported in cases where an equivalent dose of more than $20 \mathrm{~Gy}$ is administered. In summary, high control rates have been reported in all RT schemes for cutaneous lesions. In single fraction treatments below $8 \mathrm{~Gy}$, efficacy of RT is lower. More effective results are obtained in fractionated schemes that total doses of 20 Gy or more.[1] 


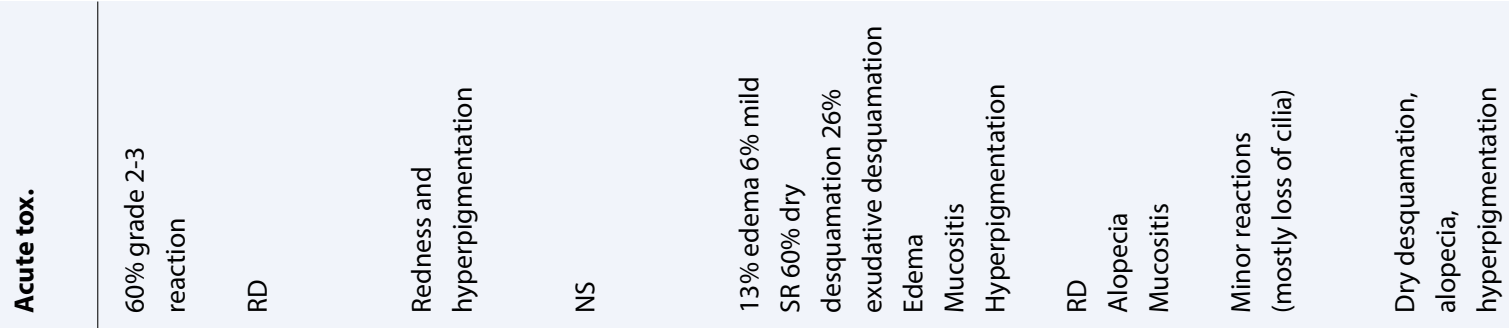



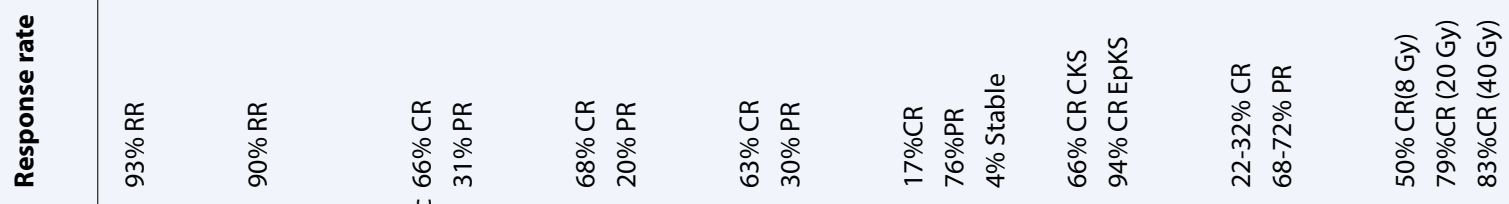

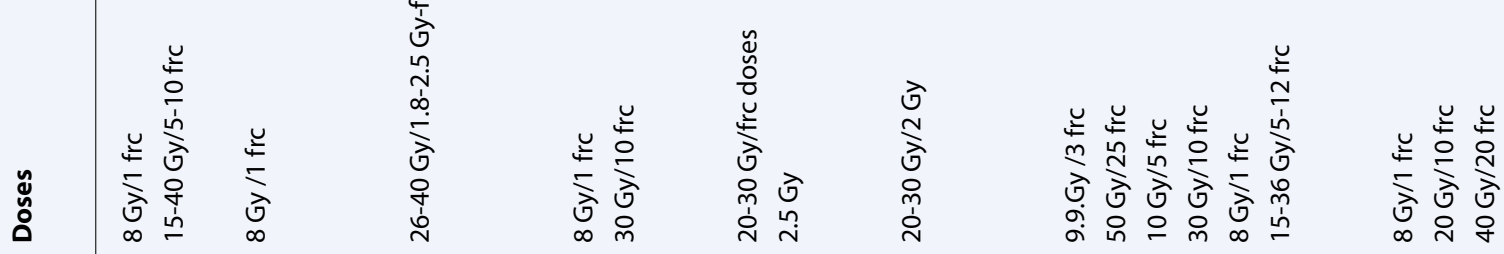

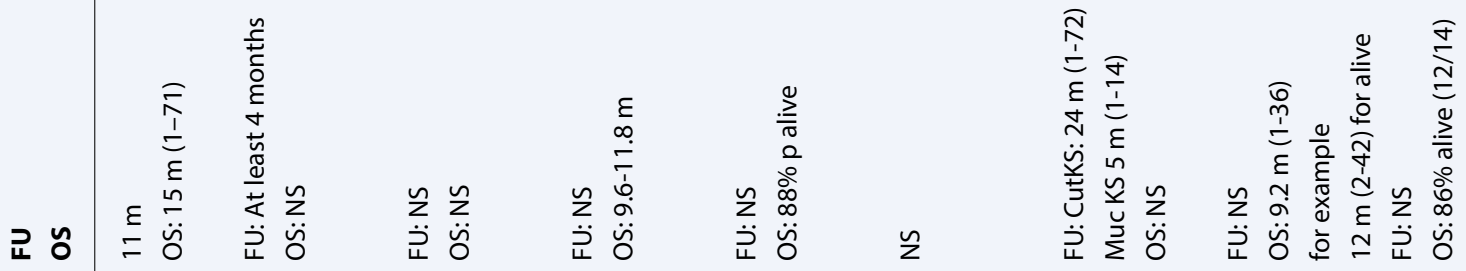

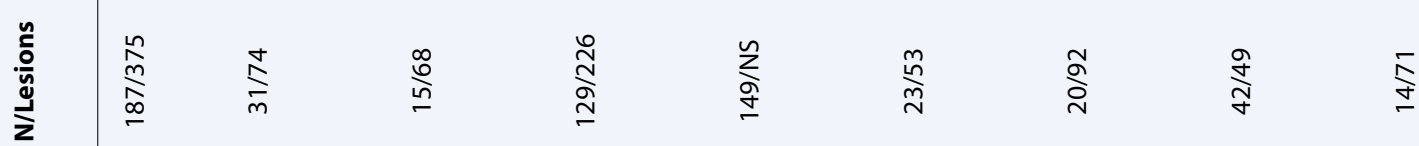

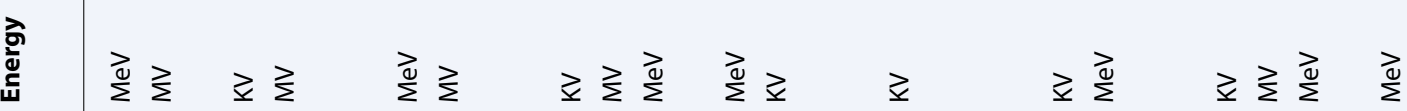

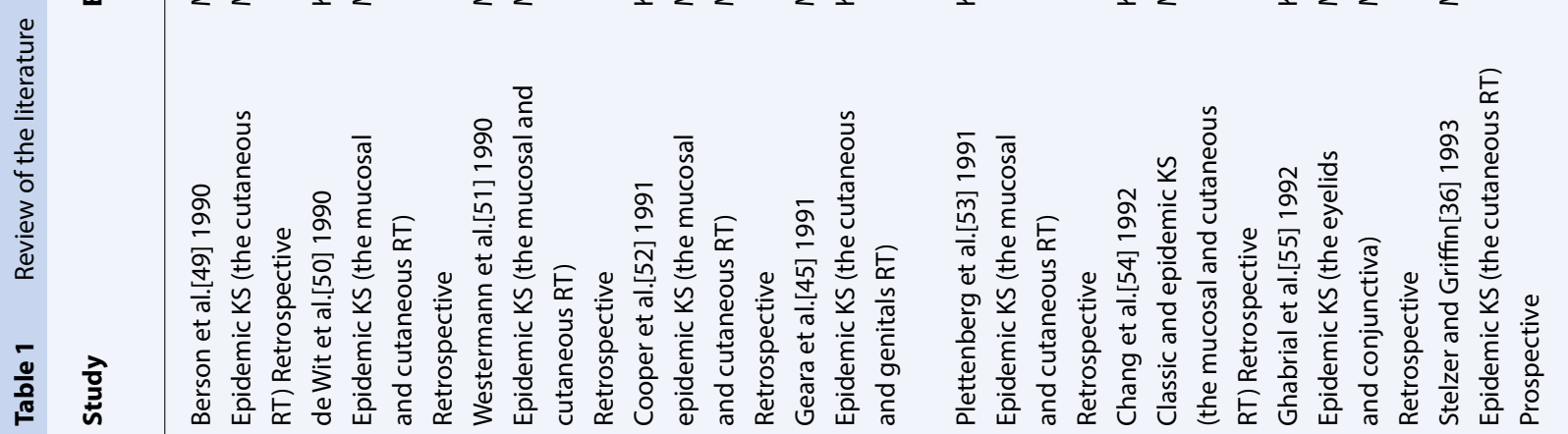




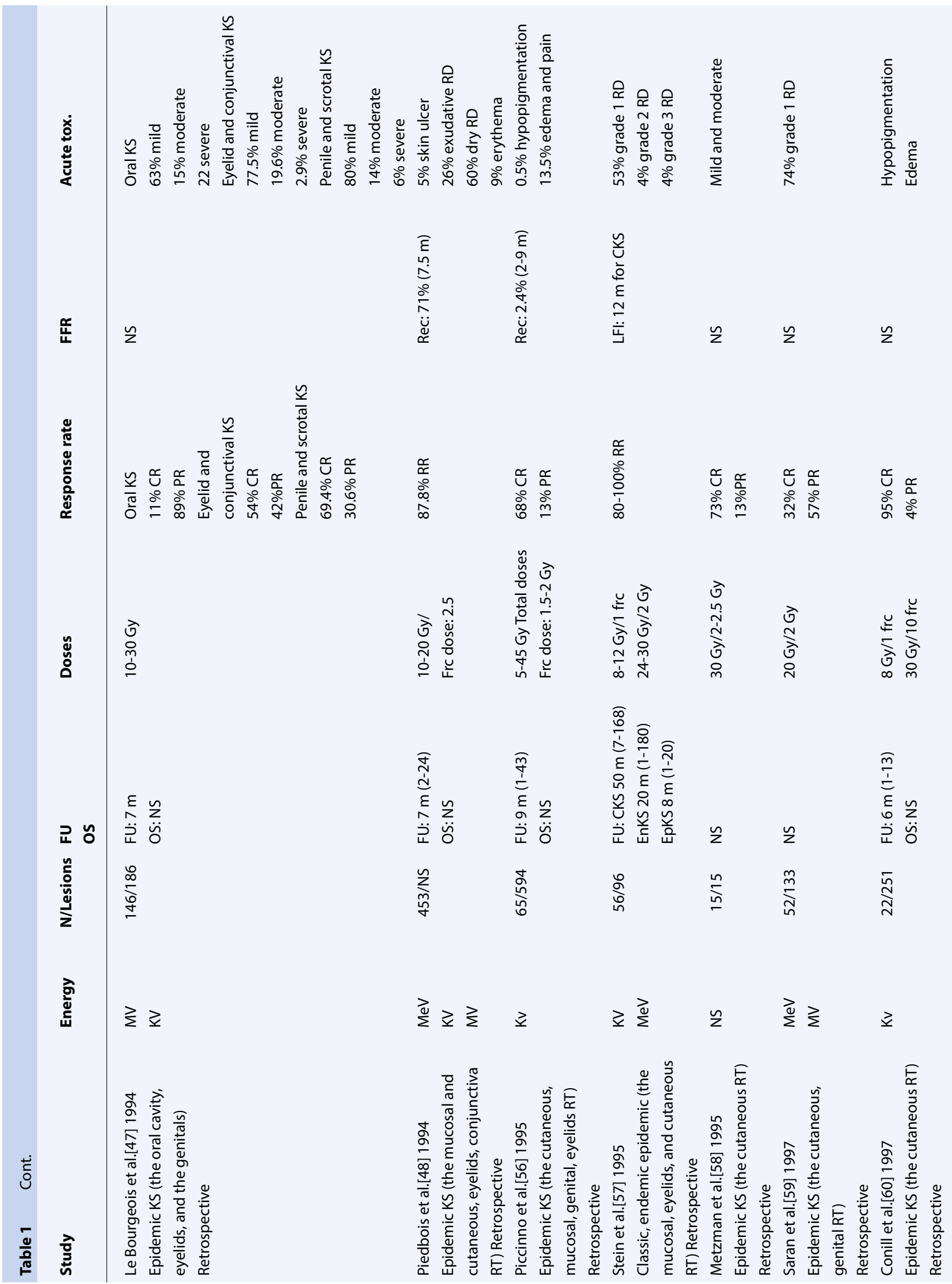




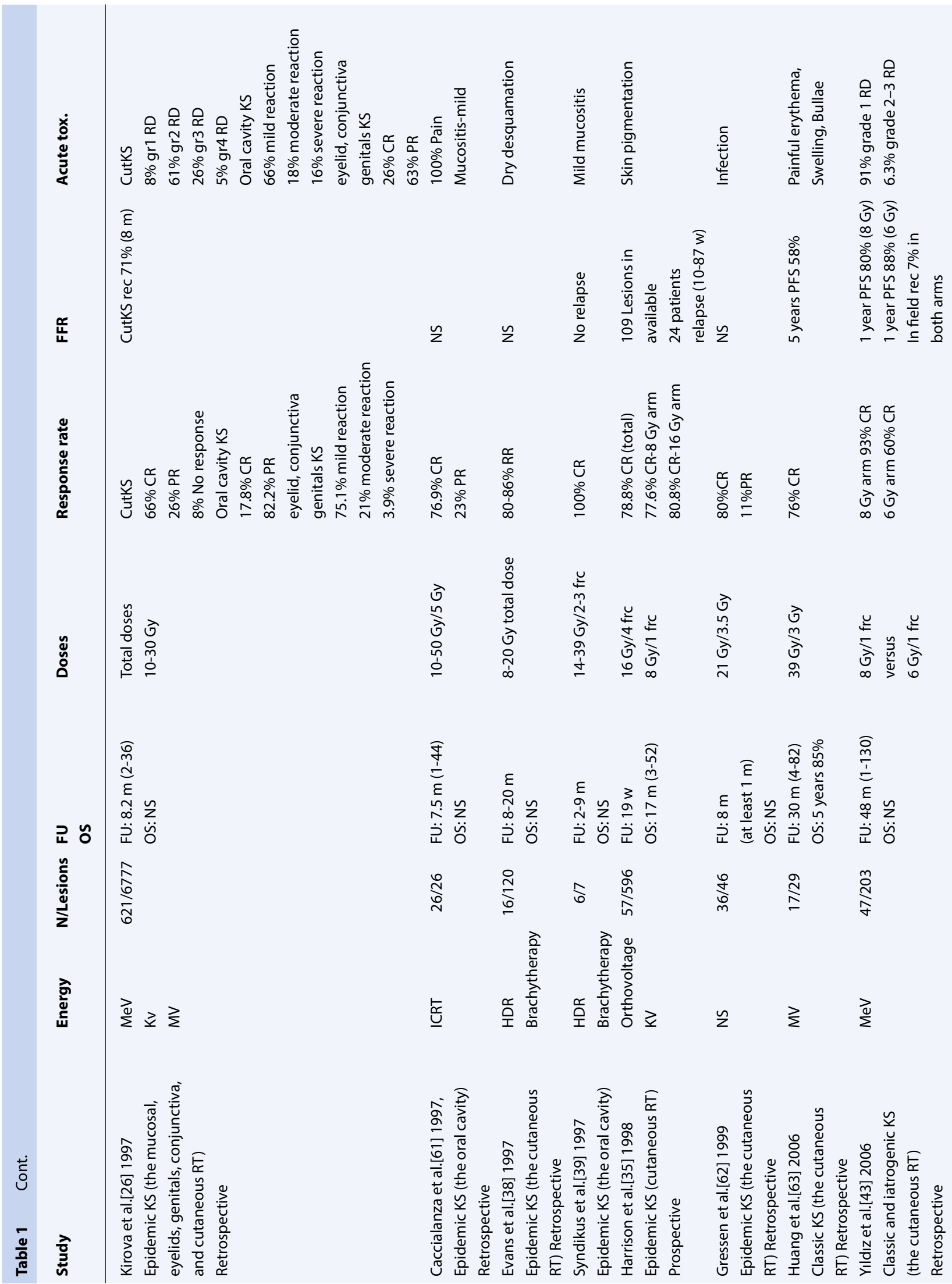




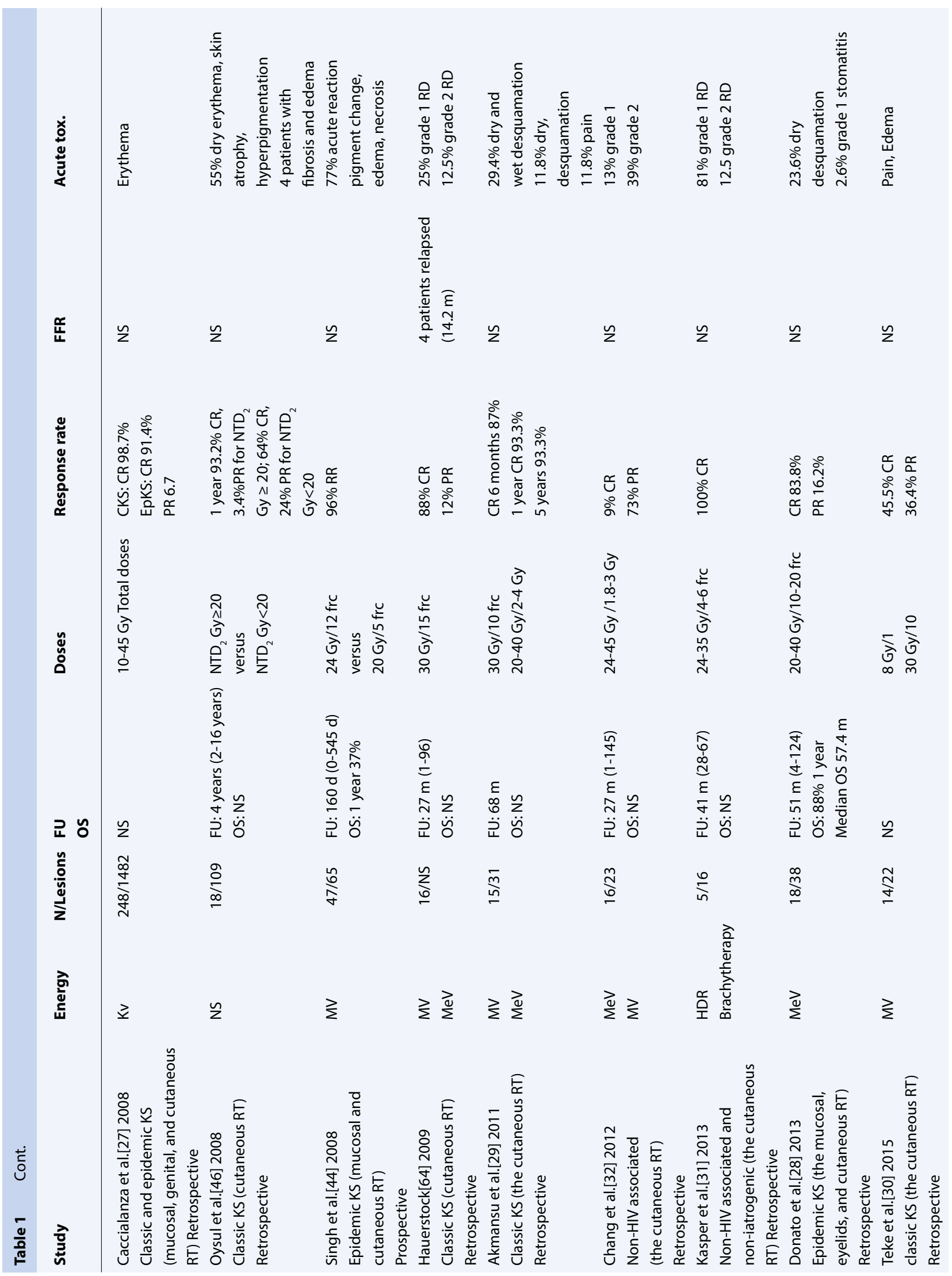


RT can also be applied successfully in extracuta-

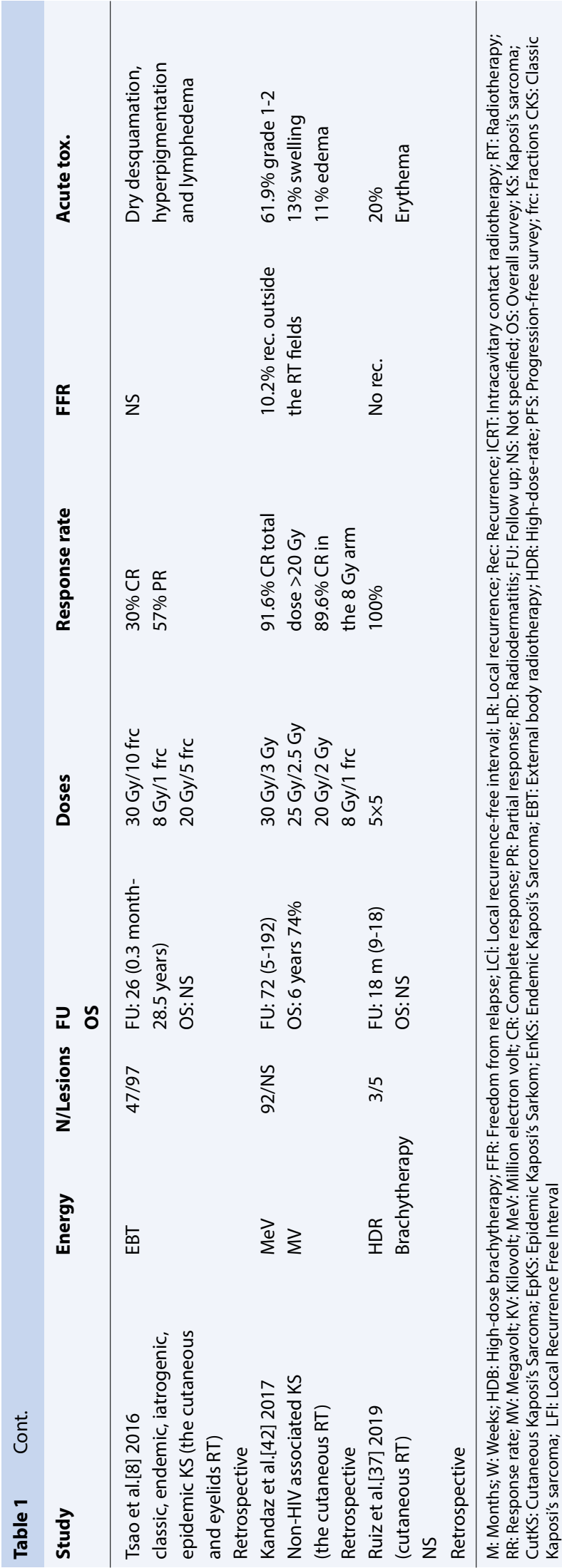
neous lesions. Eyelid and conjunctival KS are known to be more radiosensitive and have a higher response rate than cutaneous forms (Table 1).[35] In Le Bourgeois's study, they recommended 15 Gy for oral lesions; 20 Gy for eyelid conjunctival and scrotal lesions.[47] Similarly, in the series of 643 patients of Kirova et al.,[26] $15 \mathrm{~Gy}$ for oral lesions; $20 \mathrm{~Gy}$ for eyelid conjunctiva and genital lesions; and $30 \mathrm{~Gy}$ for cutaneous lesions are recommended. In the study of Piedbois et al.[48] (early 1990), 453 patients were evaluated. This study suggests that $15 \mathrm{~Gy}$ for oral lesions, eyelid conjunctive scrotal, penile-anal hand, and foot $20 \mathrm{~Gy}$ and $30 \mathrm{~Gy}$ for cutaneous lesions of the other region was sufficient. Kirova et al.[26] the first $10 \mathrm{~Gy}$ was applied, then a 10-day break, then the remaining 10 Gy was applied. Moreover, weekly follow-up was recommended to patients with eyelid, conjunctiva, lips, and genitals KS. In addition, it is recommended that the daily dose be administered as 1.5-1.6 Gy due to the risk of mucositis. [34]

Planning target volume (PTV) is created with 2-5 $\mathrm{mm}$ in orthovoltage devices and $0.5-2 \mathrm{~cm}$ margin in other treatments.[1,41] The first control is the $4^{\text {th }}$ week after the end of RT. For other areas, the patient should be called for control after 1-2 weeks.[41]

\section{Side Effects}

Most of the RT side effects are mild and moderate, and the patients have a high treatment tolerance. Grade 1 radiodermatitis (RD) is most commonly observed. Oral lesions are common, especially in HIV-associated KS patients and RT and mucositis can be observed. In general, it is aimed to reduce side effects by reducing the total and fraction dose of mucosal RT.[34]

\section{Conclusion}

RT is an effective and safe treatment for local treatment of KS in all subtypes. It is usually applied with electron or low energy photon bolus support. High control rates have been reported in all RT schemes. When the literature is examined in terms of dose and schema, for cutaneous lesions, single fraction treatments $<8$ Gy are less effective in terms of $\mathrm{CR}$, and more effective results were obtained in total doses of 20 Gy and above. A total of 15 Gy for oral lesions, $20 \mathrm{~Gy}$ in eyelid conjunctival and scrotal lesions, and $30 \mathrm{~Gy}$ for cutaneous lesions are recommended. PTV margins are defined as $2-5 \mathrm{~mm}$ for orthovoltage devices and $0.5-2 \mathrm{~cm}$ for other treatments. 


\section{Future Perspective}

Prospective randomized trials comparing different local therapies are needed. In terms of RT, dosimetric studies comparing the efficacy of different RT techniques (3D vs. IMRT vs. IGRT, etc.) should be supported by clinical studies.

Peer-review: Externally peer-reviewed.

Conflict of Interest: Authors declare no conflict of interest. Financial Support: No financial support has been used for this study.

\section{References}

1. Becker G, Bottke D. Radiotherapy in the management of Kaposi's sarcoma. Onkologie 2006;29(7):329-33.

2. GLOBOCAN 2018: Estimated Cancer Incidence, Mortality and Prevalence Worldwide; 2018. Available at: https://www.gco.iarc.fr/today/data/factsheets/populations/900-world-fact-sheets.pdf.

3. Dalla Pria A, Pinato DJ, Bracchi M, Bower M. Recent advances in HIV-associated Kaposi sarcoma. F1000Res 2019;8: F1000 Faculty Rev-970.

4. El-Mallawany NK, Villiera J, Kamiyango W, PeckhamGregory EC, Scheurer ME, Allen CE, et al. Endemic Kaposi sarcoma in HIV-negative children and adolescents: An evaluation of overlapping and distinct clinical features in comparison with HIV-related disease. Infect Agent Cancer 2018;13:33.

5. Orem J. Cancer prevention and control: Kaposis sarcoma. Ecancermedicalscience 2019;13:951.

6. Lebbe C, Garbe C, Stratigos AJ, Harwood C, Peris K, Marmol VD, et al. Diagnosis and treatment of Kaposi's sarcoma: European consensus-based interdisciplinary guideline (EDF/EADO/EORTC). Eur J Cancer 2019;114:117-27.

7. Cheng ST, Ke CL, Lee CH, Wu CS, Chen GS, Hu SC. Dermoscopic rainbow pattern in non-Kaposi sarcoma lesions reply. Br J Dermatol 2010;162(2):458-9.

8. Tsao MN, Sinclair E, Assaad D, Fialkov J, Antonyshyn O, Barnes E. Radiation therapy for the treatment of skin Kaposi sarcoma. Ann Palliat Med 2016;5(4):298302.

9. Fatahzadeh M. Kaposi sarcoma: Review and medical management update. Oral Surg Oral Med Oral Pathol Oral Radiol 2012;113(1):2-16.

10. Karakas Y, Aksoy S, Gullu HI. Kaposi's sarcoma epidemiology, risk factors, staging and treatment: An overview. Acta Oncol Turc 2017;20:148-59.

11. Ruocco E, Ruocco V, Tornesello ML, Gambardella A,
Wolf R, Buonaguro FM. Kaposi's sarcoma: Etiology and pathogenesis, inducing factors, causal associations, and treatments: Facts and controversies. Clin Dermatol 2013;31(4):413-22.

12. Régnier-Rosencher E, Guillot B, Dupin N. Treatments for classic Kaposi sarcoma: A systematic review of the literature. J Am Acad Dermatol 2013;68(2):313-311.

13. Vangipuram R, Tyring SK. Epidemiology of Kaposi sarcoma: Review and description of the nonepidemic variant. Int J Dermatol 2019;58(5):538-42.

14. Dutz W, Stout AP. Kaposi's sarcoma in infants and children. Cancer 1960;13:684-94.

15. Davies JN, Lothe F. Kaposi's sarcoma in African children. Acta Unio Int Contra Cancrum 1962;18:394-9.

16. Slavin G, Cameron HM, Forbes C, Mitchell RM. Kaposi's sarcoma in East African children: A report of 51 cases. J Pathol 1970;100(3):187-99.

17. Curtiss P, Strazzulla LC, Friedman-Kien AE. An update on Kaposi's sarcoma: Epidemiology, pathogenesis and treatment. Dermatol Ther (Heidelb) 2016;6(4):46570 .

18. Nicolini G, Abraham S, Fogliata A, Jordaan A, Clivio A, Vanetti E, et al. Critical appraisal of volumetric-modulated arc therapy compared with electrons for the radiotherapy of cutaneous Kaposi's sarcoma of lower extremities with bone sparing. Br J Radiol 2013;86(1023):20120543.

19. Rabate C. Prise en charge du sarcome de Kaposi posttransplantation re'nale en $1^{\wedge}$ le de France: Analyse re'trospective de 89 patients. Ann Dermatol Venereol 2013;140:404.

20. Hoffmann C, Sabranski M, Esser S. HIV-associated Kaposi's sarcoma. Oncol Res Treat 2017;40(3):94-8.

21. Brambilla L, Bellinvia M, Tourlaki A, Scoppio B, Gaiani F, Boneschi V. Intralesional vincristine as first-line therapy for nodular lesions in classic Kaposi sarcoma: A prospective study in 151 patients. Br J Dermatol 2010;162(4):854-9.

22. Di Monta G, Caracò C, Benedetto L, La Padula S, Marone U, Tornesello ML, et al. Electrochemotherapy as "new standard of care" treatment for cutaneous Kaposi's sarcoma. Eur J Surg Oncol 2014;40(1):61-6.

23. Latini A, Bonadies A, Trento E, Bultrini S, Cota C, Solivetti FM, et al. Effective treatment of Kaposi's sarcoma by electrochemotherapy and intravenous bleomycin administration. Dermatol Ther 2012;25(2):214-8.

24. Curatolo P, Quaglino P, Marenco F, Mancini M, Nardò $\mathrm{T}$, Mortera $\mathrm{C}$, et al. Electrochemotherapy in the treatment of Kaposi sarcoma cutaneous lesions: A twocenter prospective phase II trial. Ann Surg Oncol 2012;19(1):192-8.

25. Di Lorenzo G. Update on classic Kaposi sarcoma ther- 
apy: New look at an old disease. Crit Rev Oncol Hematol 2008;68(3):242-9.

26. Kirova YM, Belembaogo E, Frikha H, Haddad E, Calitchi E, Levy E, et al. Radiotherapy in the management of epidemic Kaposi's sarcoma: A retrospective study of 643 cases. Radiother Oncol 1998;46(1):19-22.

27. Caccialanza M, Marca S, Piccinno R, Eulisse G. Radiotherapy of classic and human immunodeficiency virus-related Kaposi's sarcoma: Results in 1482 lesions. J Eur Acad Dermatol Venereol 2008;22(3):297-302.

28. Donato V, Guarnaccia R, Dognini J, de Pascalis G, Caruso C, Bellagamba R, et al. Radiation therapy in the treatment of HIV-related Kaposi's sarcoma. Anticancer Res 2013;33(5):2153-7.

29. Akmansu M, Göksel F, Erpolat OP, Unsal D, Karahacioglu $\mathrm{E}$, Bora $\mathrm{H}$. The palliative radiotherapy of classic Kaposi's sarcoma of foot region: Retrospective evaluation. UHOD 2011;3:147-52.

30. Teke F, Akkurt ZM, Yıldırım O, Teke M, Zincircioğlu SB. Evaluation of 14 patients performed radiotherapy due to Kaposi sarcoma. Dicle Med J 2015;42:326-30.

31. Kasper ME, Richter S, Warren N, Benda R, Shang C, Ouhib Z. Complete response of endemic Kaposi sarcoma lesions with high-dose-rate brachytherapy: Treatment method, results, and toxicity using skin surface applicators. Brachytherapy 2013;12(5):495-9.

32. Chang JH, Kim IH. Role of radiotherapy in local control of non-AIDS associated Kaposi's sarcoma patients in Korea: A single institution experience. Radiat Oncol J 2012;30(4):153-7.

33. Park JM, Kim IH, Ye SJ, Kim K. Evaluation of treatment plans using various treatment techniques for the radiotherapy of cutaneous Kaposi's sarcoma developed on the skin of feet. J Appl Clin Med Phys 2014;15(6):4970.

34. Niewald M, Rübe C. Kaposi's sarcoma--radiotherapeutic aspects. Front Radiat Ther Oncol 2006;39:50-8.

35. Harrison M, Harrington KJ, Tomlinson DR, Stewart JS. Response and cosmetic outcome of two fractionation regimens for AIDS-related Kaposi's sarcoma. Radiother Oncol 1998;46(1):23-8.

36. Stelzer KJ, Griffin TW. A randomized prospective trial of radiation therapy for AIDS-associated Kaposi's sarcoma. Int J Radiat Oncol Biol Phys 1993;27(5):105761.

37. Ruiz MÁ, Rivero JQ, García JL, Rodríguez JJ, Kavadoy YR, Carmona MF, et al. High-dose-rate brachytherapy in the treatment of skin Kaposi sarcoma. J Contemp Brachytherapy 2017;9(6):561-5.

38. Evans MD, Yassa M, Podgorsak EB, Roman TN, Schreiner LJ, Souhami L. Surface applicators for high dose rate brachytherapy in AIDS-related Kaposi's sar- coma. Int J Radiat Oncol Biol Phys 1997;39(3):769-74.

39. Syndikus I, Vinall A, Rogers P, Spittle M. High dose rate microselectron moulds for Kaposi sarcoma of the palate. Radiother Oncol 1997;42(2):167-70.

40. Saw CB, Wen BC, Anderson K, Pennington E, Hussey DH. Dosimetric considerations of water-based bolus for irradiation of extremities. Med Dosim 1998;23(4):292-5.

41. Available at: http://www.londoncancer.org/media/76382/london-cancer-skin-radiotherapy-guidelines-2013-v1.0.pdf.

42. Kandaz M, Bahat Z, Guler OC, Canyilmaz E, Melikoglu M, Yoney A. Radiotherapy in the management of classic Kaposi's sarcoma: A single institution experience from Northeast Turkey. Dermatol Ther 2018;31(4):e12605.

43. Yildiz F, Genc M, Akyurek S, Cengiz M, Ozyar E, Selek $\mathrm{U}$, et al. Radiotherapy in the management of Kaposi's sarcoma: Comparison of 8 Gy versus $6 \mathrm{~Gy}$. J Natl Med Assoc 2006;98(7):1136-9.

44. Singh NB, Lakier RH, Donde B. Hypofractionated radiation therapy in the treatment of epidemic Kaposi sarcoma--a prospective randomized trial. Radiother Oncol 2008;88(2):211-6.

45. Geara F, Le Bourgeois JP, Piedbois P, Pavlovitch JM, Mazeron JJ. Radiotherapy in the management of cutaneous epidemic Kaposi's sarcoma. Int J Radiat Oncol Biol Phys 1991;21(6):1517-22.

46. Oysul K, Beyzadeoglu M, Surenkok S, Ozyigit G, Dirican B. A dose-response analysis for classical Kaposi's sarcoma management by radiotherapy. Saudi Med J 2008;29(6):837-40.

47. Le Bourgeois JP, Frikha H, Piedbois P, Le Péchoux C, Martin L, Haddad E. Radiotherapy in the management of epidemic Kaposi's sarcoma of the oral cavity, the eyelid and the genitals. Radiother Oncol 1994;30(3):263-6.

48. Piedbois P, Frikha H, Martin L, Levy E, Haddad E, Le Bourgeois JP. Radiotherapy in the management of epidemic Kaposi's sarcoma. Int J Radiat Oncol Biol Phys 1994;30(5):1207-11.

49. Berson AM, Quivey JM, Harris JW, Wara WM. Radiation therapy for AIDS-related Kaposi's Sarcoma. Int J Radiat Oncol Biol Phys 1990;19(3):569-75.

50. de Wit R, Smit WG, Veenhof KH, Bakker PJ, Oldenburger F, González DG. Palliative radiation therapy for AIDS-associated Kaposi's sarcoma by using a single fraction of 800 cGy. Radiother Oncol 1990;19(2):1316.

51. Westermann VA, Müller RP, Adler M, Bendick C, Rasokat H. The radiotherapy of epidemic Kaposis sarcomas in AIDS patients. Strahlenther Onkol 
1990;166(11):705-9.

52. Cooper JS, Steinfeld AD, Lerch I. Intentions and outcomes in the radiotherapeutic management of epidemic Kaposi's sarcoma. Int J Radiat Oncol Biol Phys 1991;20(3):419-22.

53. Plettenberg A, Janik I, Kolb H, Meigel W. Local therapy measures in HIV-associated Kaposi's sarcoma with special reference to fractionation radiotherapy. Strahlenther Onkol 1991;167(4):208-13.

54. Chang LF, Reddy S, Shidnia H. Comparison of radiation therapy of classic and epidemic Kaposi's sarcoma. Am J Clin Oncol 1992;15(3):200-6.

55. Ghabrial R, Quivey JM, Dunn JP Jr., Char DH. Radiation therapy of acquired immunodeficiency syndrome-related Kaposi's sarcoma of the eyelids and conjunctiva. Arch Ophthalmol 1992;110(10):1423-6.

56. Piccinno R, Caccialanza M, Cusini M. Role of radiotherapy in the treatment of epidemic Kaposi's sarcoma: Experience with sixty-five cases. J Am Acad Dermatol 1995;32:1000-3.

57. Stein ME, Lakier R, Spencer D, Dale J, Kuten A, MacPhail P, et al. Radiation therapy for non-AIDS associated (classic and endemic African) and epidemic Kaposi's sarcoma. Int J Radiat Oncol Biol Phys 1994;28(3):613-9.
58. Metzmann U, Rösler HP, Kutzner J. The palliative radiotherapy of Kaposi's sarcomas in AIDS patients. Strahlenther Onkol 1995;171(4):238-40.

59. Saran FH, Adamietz IA, Thilmann C, Mose S, Böttcher HD. HIV-associated cutaneous Kaposi's sarcoma-palliative local treatment by radiotherapy. Acta Oncol 1997;36(1):55-8.

60. Conill C, Alsina M, Verger E, Henríquez I. Radiation therapy in AIDS-related cutaneous Kaposi's sarcoma. Dermatology 1997;195(1):40-2.

61. Caccialanza M, Piccinno R, Gnecchi L, Beretta M, Cusini M. Intracavitary contact X-ray therapy of oral HIV-associated Kaposi's sarcoma. Int J STD AIDS 1997;8(9):581-4.

62. Gressen EL, Rosenstock JG, Xie Y, Corn BW. Palliative treatment of epidemic Kaposi sarcoma of the feet. Am J Clin Oncol 1999;22(3):286-90.

63. Huang KM, Hsu CH, Cheng JC, Lai MK, Jeng SC, Ting LL, et al. Radiotherapy of classic Kaposi's sarcoma in Taiwan, an area where classic Kaposi's sarcoma is not prevalent. Anticancer Res 2006;26(6C):4659-63.

64. Hauerstock D, Gerstein W, Vuong T. Results of radiation therapy for treatment of classic Kaposi sarcoma. J Cutan Med Surg 2009;13(1):18-21. 